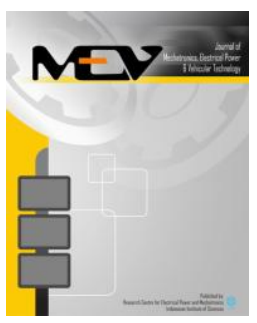

Journal of Mechatronics, Electrical Power, and Vehicular Technology

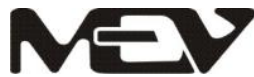

\title{
MODELING AND DESIGN OF COOPERATIVE BRAKING IN ELECTRIC AND HYBRID VEHICLES USING INDUCTION MACHINE AND HYDRAULIC BRAKE
}

\author{
Zaini Dalimus $^{\text {a,**, Khallid Hussain }}{ }^{\text {b }}$, Andrew J. Day ${ }^{\text {b }}$ \\ ${ }^{a}$ Electrical Engineering Department, Andalas University, Indonesia \\ ${ }^{\mathrm{b}}$ School of Engineering, Design and Technology, University of Bradford, U.K
}

Received 19 January 2016; received in revised form 24 May 2016; accepted 24 May 2016

Published online 29 July 2016

\begin{abstract}
In mixed-mode braking applications, the electric motor/generator(M/G) and hydraulic pressure valve are controlled to meet the driver's braking demand. Controlling these braking elements is achieved by modulating the current generated by the $\mathrm{M} / \mathrm{G}$ and adjusting the fluid pressure to the wheel brake cylinders. This paper aims to model and design combined regenerative and hydraulic braking systems which, comprise an induction electric machine, inverter, NiMH battery, controller, a pressure source, pressure control unit, and brake calipers. A $15 \mathrm{~kW}$ $1500 \mathrm{rpm}$ induction machine equipped with a reduction gear having a gear ratio of 4 is used. A hydraulic brake capable to produce fluid pressure up to 40 bar is used. Direct torque control and pressure control are chosen as the control criteria in the $\mathrm{M} / \mathrm{G}$ and the hydraulic solenoid valve. The braking demands for the system are derived from the Federal Testing Procedure (FTP) drive cycle. Two simulation models have been developed in Matlab $^{\circledR} /$ Simulink ${ }^{\circledR}$ to analyze the performance of the control strategy in each braking system. The developed model is validated through experiment. It is concluded that the control system does introduce torque ripple and pressure oscillation in the braking system, but these effects do not affect vehicle braking performance due to the high frequency nature of pressure fluctuation and the damping effect of the vehicle inertia. Moreover, experiment results prove the effectiveness of the developed model.
\end{abstract}

Keywords: mixed-mode braking; regenerative brake; induction machine; hydraulic brake; direct torque; pulse-wide modulation.

\section{INTRODUCTION}

In a conventional vehicle, braking is provided by the friction on each wheel. The kinetic energy is transformed into heat energy through the process of friction between the two surfaces in contact in the brake; the rotor and the stator. A conventional braking system has been modeled, and it was confirmed through experiment that energy loss during braking appeared in a rear drummed brake temperature rise [1]. Meanwhile, a hybrid electric vehicle allows the kinetic energy to be converted into electrical energy using an electric Motor/Generator $(M / G)$, stored in a battery or an ultra-capacitor and subsequently returned to the $\mathrm{M} / \mathrm{G}$, and this is known as regenerative braking. Since the M/G capacity to

\footnotetext{
* Corresponding Author.Tel: +6281266224644
}

E-mail: zzaini21@gmail.com absorb braking energy is limited, the hydraulic brake must be controlled to meet the driver's demand. The challenge is how to control both regenerative and hydraulic braking systems accurately and effectively, so the braking performance remains the same as the conventional vehicle.

Many $\mathrm{M} / \mathrm{Gs}$ have been applied in Electric Vehicles (EVs) and hybrid EVs, such as Permanent Magnet Brushless (PMBL) drive in the Toyota Prius and induction drive in the GM EV1 [2]. The advantages of the PMBL drive include high efficiency, high torque density, and high reliability. However, an induction motor is a better choice in terms of lower material and manufacturing costs, and higher durability. It also offers energy saving in free-wheel operation and more flexibility of flux control [3]. 
Typical control techniques applied in the PMBL drives are efficiency optimizing, direct torque, artificial intelligence, and position-sensor less controls. Direct Torque Control (DTC) constitutes the closed-loop control system where the controlled state variables are torque and stator flux without a current controller [4]. Two common techniques are switching-table-based hysteresis and constant-switching-frequency with space-vector modulation. These work on the principle that the electromagnetic torque can be controlled by changing the load angle for a constant stator flux linkage, where the load angle is the angle between the stator and permanent magnet flux linkage vectors [5].

As in electrical drives for vehicle applications, the conventional braking system has evolved to incorporate advanced feature onboard. For instance, an electrically-assisted actuation called e-ACT was developed and implemented in the Nissan Leaf car [6]. To generate pressure in the master cylinder, the vacuum booster was replaced by an electric motor. A stroke sensor in the brake pedal measured the driver's demand (i.e. the force applied by the driver to the brake pedal) and transmitted it to the Engine Control Unit (ECU) to distribute into regenerative and friction portions. Pressure modulation is performed by a linear solenoid valve that allows a smooth pressure rise during braking. The Proportional-Integral-Derivative (PID) technique is used to control solenoid current producing the magnetic force [7]. Park et al. [8] conducted an experiment to find the pressure-current relation in Normally Open (NO) and Normally Closed (NC) valves. In the $\mathrm{NO}$ valve, the current maintains the pressure difference between the master cylinder and the wheel when the valve was closed, while the current was supplied to the $\mathrm{NC}$ valve to allow fluid pressure from the wheel cylinder. It was found that the pressure-current relation in these valves is linear.

Experimental work has shown that regenerative-friction blending can successfully meet the brake demand, though small errors between target and operated brake forces were observed [6]. Aoki et al. [9] also investigated the hydraulic brake response in mixed mode braking and found that the target pressure followed the control pressure closely. In another experimental work by Albrichsfeld et al. [10], regenerative and friction brake were blended to stop the vehicle from $90 \mathrm{~km} / \mathrm{h}$ in 8 seconds without adversely affecting the vehicle deceleration. It shows that at a pedal stroke of $10 \mathrm{~mm}$, the vehicle deceleration was constant at $0.36 \mathrm{~g}$. Lei et al. [11] simulated brake blending between regenerative and anti- lock braking system where the electric motor and hydraulic brake were modeled by simple transfer functions. The model was simulated on the roads with low and high friction coefficient. However, the blending performance could not be analyzed accurately as in the experimental work previously mentioned.

In this paper, dynamic models of both regenerative braking and friction braking are developed and proved through experiment. The paper is organized so that in section II, a model of an induction motor, inverter, and battery as the primary components of regenerative braking are derived together with a controller employing direct torque control technique. In section III, a friction braking model is developed consisting of many components, including accumulator, solenoid valve and wheel cylinder. A pressure control criterion as the control scheme is also presented. The simulations to implement the dynamic models are presented in section IV. Section V describes validation of the developed model through experiments. Finally, the conclusions are drawn in section VI.

\section{REgenerative BRAKE MODEL}

A schematic diagram of the regenerative braking system is shown in Figure 1. The current flows from the induction motor to the battery in braking mode and vice versa in traction mode. The torque controller uses voltages, currents, and rotor position measurements to switch on or off the three-phase inverter. To match the voltage level of the inverter and the battery and generate smooth battery current, a DC link is needed.

Table 1 shows important parameters of regenerative brake components namely induction motor, battery, and DC link. In some cases, DCDC booster is needed to increase the battery voltage but, here, it was not considered. The DC link was then represented by inductor and capacitor.

The machine equations in the $d q$ reference frame are as described in equations (1) - (5).

$$
\begin{aligned}
& \psi_{d}=L_{d} i_{d}+\psi_{m} \\
& \psi_{q}=L_{q} i_{q} \\
& u_{d}=R_{s} i_{d}+\frac{d \psi_{d}}{d t}-\omega_{r} \psi_{q}
\end{aligned}
$$

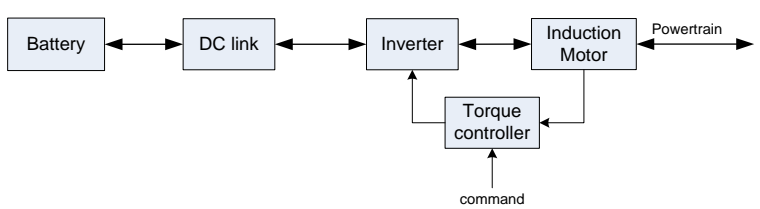

Figure 1. Electrical traction/braking system in the hybrid vehicle 


$$
\begin{aligned}
& u_{q}=R_{s} i_{q}+\frac{d \psi_{q}}{d t}-\omega_{r} \psi_{d} \\
& T_{e}=\frac{3 p}{2}\left(\psi_{d} i_{q}-\psi_{q} i_{d}\right)
\end{aligned}
$$

An inverter is an electronic switch used to convert DC voltage into AC voltage at a specified amplitude and frequency. In a high power electric drive, insulated-gate bipolar transistor (IGBT) switches are widely used due to their high switching frequency, high impedance gate and small ON state voltage. During traction operation, power flows from the DC source to the electric $M / G$ through the inverter. Meanwhile, the $\mathrm{M} / \mathrm{G}$ acts as a generator during braking and generates AC voltage across the terminal. Then, the inverter converts the generated voltage into DC form and stores electrical energy in the battery. In this case, the inverter operates as a rectifier.

Three types of battery are commercially available for HEV and EV application; these are lead-acid, nickel metal hydride (NiMH), and lithium ion, each with their own advantages and disadvantages. Tremblay et al. [12] developed a simulation model of these batteries and also provided experimental validation. The battery was modeled by a voltage source in series with a resistance whereas the voltage magnitude is affected by many parameters. Equation (6) is for discharging, and equation (7) is for charging of NiMH battery.

$$
\begin{aligned}
V_{b a t t}= & E_{0}-R_{i} i_{b}-K \frac{Q_{b}}{Q_{b}-i t}\left(i t+i^{*}\right)+ \\
& \operatorname{Exp}(t) \\
V_{b a t t}= & E_{0}-R_{i} i_{b}-K \frac{Q_{b}}{|i t|-0.1 Q_{b}} i^{*}- \\
& K \frac{Q_{b}}{Q_{b}-i t} i t+\operatorname{Exp}(t)
\end{aligned}
$$

As explained briefly in the Introduction, the load angle is modified to control the electromagnetic torque. To analyze the effect of

Table 1.

Regenerative brake parameters

\begin{tabular}{ll}
\hline Parameters & Values \\
\hline Induction motor & \\
\hline Power $(\mathrm{kW})$ & 15 \\
\hline Base speed (rpm) & 1500 \\
\hline Terminal voltage $(\mathrm{V})$ & 140 \\
\hline DC link & \\
\hline Inductance $(\mathrm{H})$ & 0.1 \\
\hline Capacitance $(\mathrm{mF})$ & 470 \\
\hline Battery & \\
\hline Open-circuit voltage $(\mathrm{V})$ & 200 \\
\hline Capacity $(\mathrm{Ah})$ & 123 \\
\hline
\end{tabular}

load angle to the torque, the currents in equation (5) can be replaced with fluxes for voltage source inverter-fed induction motor drives, and obtained:

$$
T_{e}=\frac{L_{M}}{L_{r}} \psi_{r} \frac{1}{\sigma L_{s}} \psi_{s} \sin \delta_{\psi}
$$

It shows that applying the selected voltage across motor terminals, the load angle can be increased or decreased. A switching table DTC with a circular stator flux path is used in this research as shown in Figure 2. The idea is to select an entry in the optimal switching table of the inverter based on estimation of electromagnetic torque and stator flux linkage. The stator flux linkage reference is derived from motor speed considering constant of torque and power operation.

\section{III.FRICTION BRAKE MODEL}

Unlike a conventional braking system, the hydraulic pressure is not directly controlled by the driver, but utilizes a control device in the form of a solenoid valve. To analyze the braking operation of an electro-hydraulic braking system, the hydraulic circuit of the system and the electric circuit in the solenoid valve must be modeled. The main elements of hydraulic circuit are directional valves, relief valve and brake cylinder where their parameters and values are listed in Table 2.

The solenoid valve includes an orifice which is a sudden restriction in a flow passage which may have a fixed or variable area. The pressure drop across the orifice is caused by fluid acceleration in turbulent flow, and is given by equation (9).

$$
Q=C_{d} A_{0} \frac{\sqrt{2\left(P_{1}-P_{2}\right)}}{\sqrt{\rho}}
$$

Both the discharge coefficient and the orifice are determined by the structural configuration of the control valve. There are three equations governing the dynamics of the solenoid valve as described in equations (10) - (12).

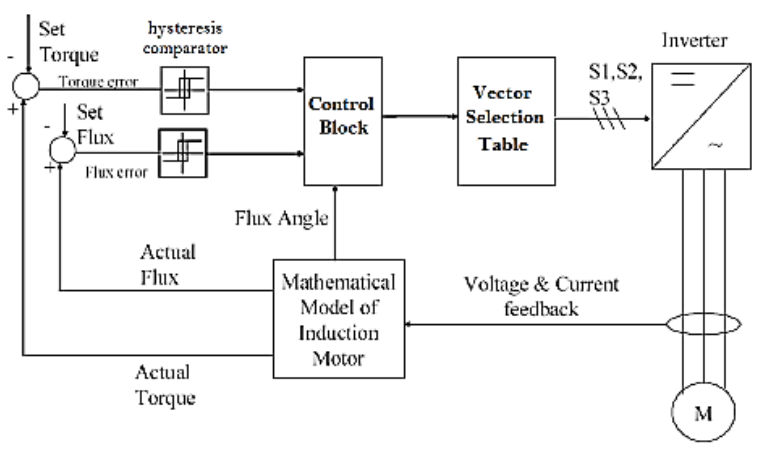

Figure 2. DTC scheme of induction motor for induction motor drives [13] 


$$
\begin{aligned}
& \frac{d_{i}}{d_{t}}= \frac{1}{L+i \frac{\partial L}{\partial i}}\left(U-R_{i}-i v \frac{\partial L}{\partial x}\right) \\
& \frac{d_{v}}{d_{t}}= \frac{1}{m}\left(F_{m}(x, i)-K\left(x+G_{0}\right)-F_{p}(x)-\right. \\
& \quad b v-F f \\
& \frac{d_{t}}{d_{t}}=v
\end{aligned}
$$

The first equation is derived from Kirchhoff's Voltage Law while the second comes from Newton's law. The relation between force and inductance to current and position is nonlinear. If the current is held constant during the movement at the iron core, the magnetic force is given by equation (13).

$$
F_{e}=\frac{1}{2} i^{2} \frac{\beta}{(\alpha+\beta x)^{2}}
$$

The Finite Element modeling of fluid field in the ABS from Qi [13] is used to calculate the hydrokinetic force as a function of valve movement. To simplify the solving of equation (10), the magnetic circuit operates in the linear region, therefore the dependence of inductance on current is ignored and by calculation on the magnetic circuit, inductance is given by equation (14).

$$
L(x)=\beta /(\alpha+\beta x)
$$

Using a finite element result from Qi [14], the inductance saturates at $0.015 \mathrm{H}$ when the current is $2 \mathrm{~A}$ regardless plunger positions. Therefore,

Table 2.

Detail specification of hydraulic brake

\begin{tabular}{ll}
\hline Parameters & Values \\
\hline Pressure relief valve & \\
\hline Maximum passage area $\left(\mathrm{cm}^{2}\right)$ & 0.1 \\
\hline Valve pressure setting $(\mathrm{bar})$ & 60 \\
\hline Valve regulation range $(\mathrm{bar})$ & 2 \\
\hline Flow discharge coefficient & 0.7 \\
\hline Critical Reynolds number & 2000 \\
\hline 2-way directional valve & \\
\hline Maximum passage area $\left(\mathrm{cm}^{2}\right)$ & 15 \\
\hline Valve maximum opening $(\mathrm{mm})$ & 5 \\
\hline Flow discharge coefficient & 0.7 \\
\hline Critical Reynolds number & 2000 \\
\hline Single-acting hydraulic cylinder & \\
\hline Piston area $\left(\mathrm{cm}^{2}\right)$ & 3.14 \\
\hline Piston stroke $(\mathrm{mm})$ & 5 \\
\hline Dead volume $\left(\mathrm{cm}^{3}\right)$ & $10^{-2}$ \\
\hline Specific heat ratio & 1.4 \\
\hline Contact stiffness $(\mathrm{N} / \mathrm{m})$ & $10^{6}$ \\
\hline Contact damping $(\mathrm{N} / \mathrm{m} / \mathrm{s})$ & 150 \\
\hline
\end{tabular}

operation in both linear and saturated regions can be approximated by equation (15).

$$
L(x)=\left\{\begin{array}{l}
\frac{\beta}{\alpha+\beta x}, i \leq 2 \\
0,015, i>2
\end{array}\right.
$$

The control variable is the solenoid voltage which is switched on or off at high frequency to generate controlled current in the electric circuit and thus control the magnetic force in the valve movement. In this simulation, one inlet valve to increase slave cylinder pressure and one outlet valve to decrease slave cylinder pressure are used in the friction braking system as shown in Figure 3 . The opening and closing operations of these valves are determined from pressure measurement, and the control criteria are:

error $>\theta_{\text {upper }} \quad$ : pressure apply control $\theta_{\text {lower }} \leq$ error $\leq \theta_{\text {upper }} \quad:$ pressure hold control error $<\theta_{\text {lower }} \quad:$ pressure dump control where the error is a difference between desired pressure and measured pressure. Firstly, pressure applied control means the inlet valve is directed to open, and the outlet valve is directed to close. Secondly, both valves are directed to close in pressure hold control. Finally, the controller commands the inlet valve to close and the outlet valve to open in pressure dump control.

\section{IV.Simulations}

In the previous research, torque demands for the FTP drive cycle have been derived, and the two results are reproduced here as shown in Figure 4 and 5 [15]. For the $15 \mathrm{~kW}$ induction motor with nominal speed of $1500 \mathrm{rpm}$ connected to the front axle via the reduction gear $(\mathrm{N}=4)$, the regenerative torque at the wheel is 382 $\mathrm{Nm}$ for vehicle speeds less than $39.5 \mathrm{~km} / \mathrm{h}$. However, the available torque is smaller in the constant power region (motor speed $>1500 \mathrm{rpm}$ ). Since torque demands are lower at higher speeds, the induction motor can provide braking torque required on these braking events. Therefore, the friction brake is only applied at very low vehicle speed to stop the vehicle safely.

The actual regenerative torque generated by the induction M/G using DTC is plotted in Figure 6. As can be seen in the figure, the actual torque

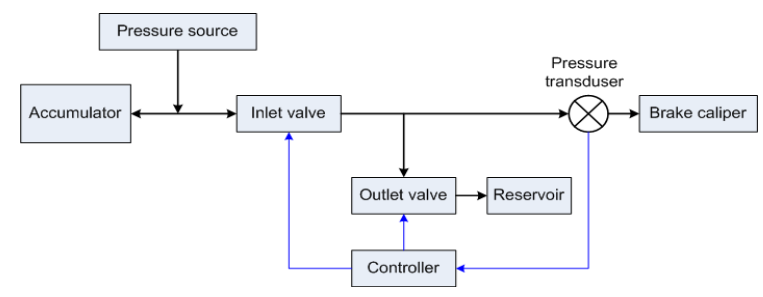

Figure 3. Friction braking model using pressure control criteria 
closely follows the desired torque though it contains high-frequency ripple (> $2 \mathrm{kHz})$ oscillating around the desired torque. Here, regenerative torque demand was obtained from torque demand from the driver, SoC, and capability curve of electric M/G. If demand is lower than the M/G capacity and SoC is not high, then the $\mathrm{M} / \mathrm{G}$ supplies the braking torque.

The above torque response can be generalized to observe all braking events in a drive cycle. However, the effect of torque ripple to the wheel speed cannot be analyzed since it is a backwardfacing simulation where the wheel speed is the input to the model. Figure 7 shows the result from the forward-facing model where the inputs are load torque and target torque. The load torque
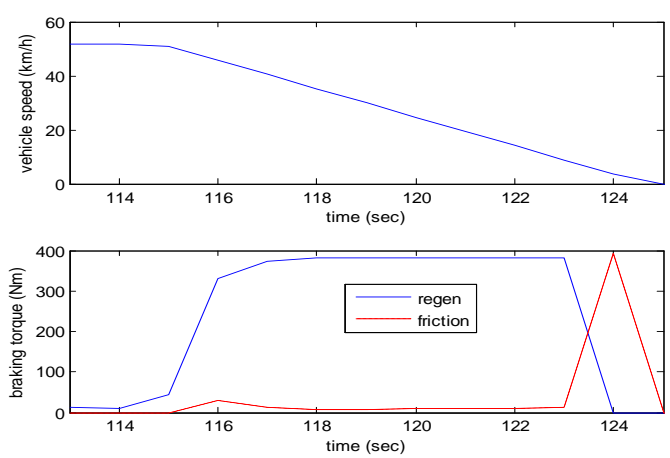

Figure 4. Torque demands (initial speed: $51.52 \mathrm{~km} / \mathrm{h}$, braking time: 12 seconds)
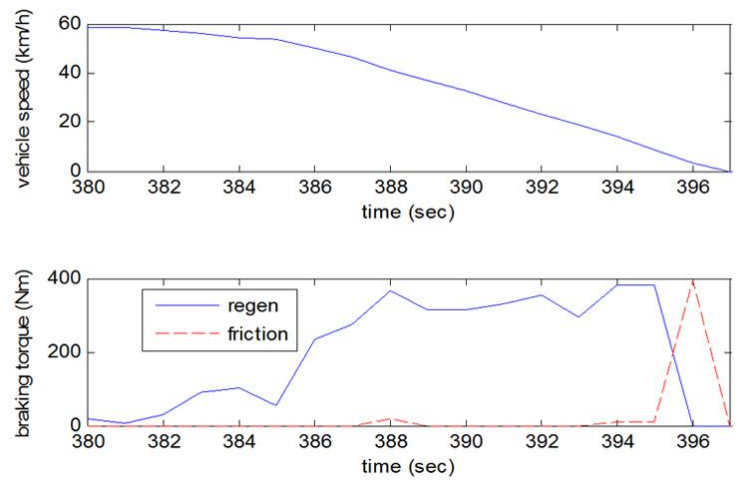

Figure 5. Torque demands (initial speed: $58.24 \mathrm{~km} / \mathrm{h}$, braking time: 17 seconds)

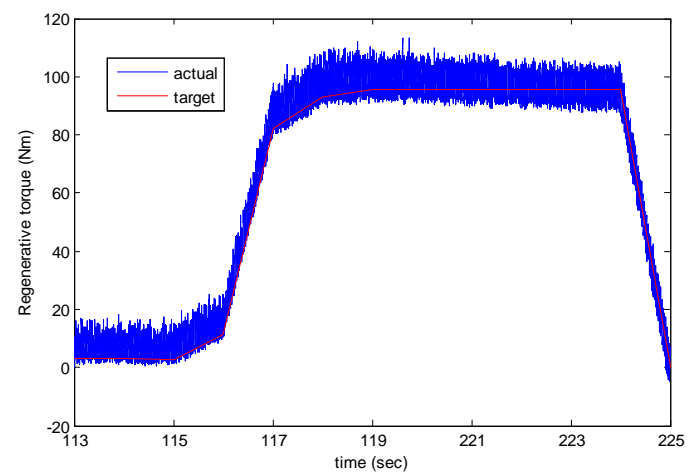

Figure 6. Torque demands (initial speed: $58.24 \mathrm{~km} / \mathrm{h}$, braking time: 17 seconds) is requested by the driver and the vehicle controller adjusts that torque according to drive capacity and forward to motor controller, called target torque. The figure tells that torque ripple caused by operation of $\mathrm{M} / \mathrm{G}$ controller does not affect vehicle comfort in terms of steady vehicle speed, thus the driver does not feel the different with conventional vehicle.

Since the regenerative brake is capable of meeting the driver's demand, the friction brake is only applied at a very low speed $(<7 \mathrm{~km} / \mathrm{h})$ as shown in Figure 8. The dotted line is the friction brake demand generated by the hydraulic braking system where it rises steadily at $\mathrm{t}=618$ seconds. The friction demand reaches its maximum value when the regenerative braking is totally disengaged at $\mathrm{t}=619$ seconds. The interval between $\mathrm{t}=617$ seconds and $\mathrm{t}=620$ seconds is reproduced in Figure 9 to highlight the wheel pressure response to follow the hydraulic brake demand. The pressure is controlled accurately although a small fluctuation can be seen.
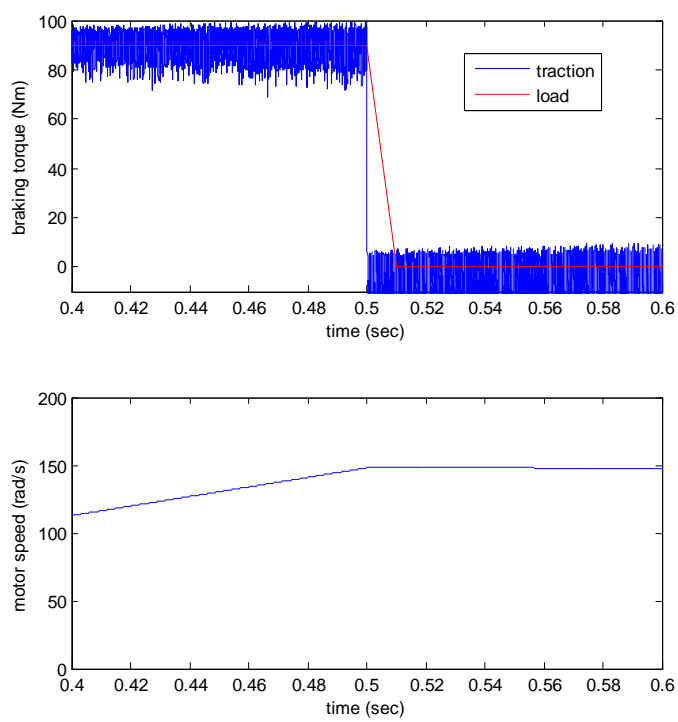

Figure 7. Torque and speed of induction motor in the forward-facing model
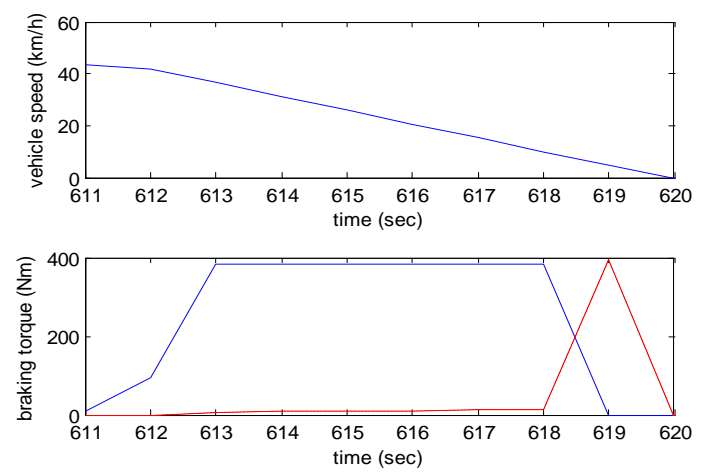

Figure 8 . Torque demands (initial speed: $42.4 \mathrm{~km} / \mathrm{h}$, braking time: 9 seconds) 


\section{VALIDATION THROUGH EXPERIMENT}

Experimental data done on Toyota Auris Hybrid was supplied by Jaguar Land Rover UK to investigate pressure control during brake blending. The vehicle was fitted with sensors to measure brake pressures, pedal force, pedal travel, vehicle speed, and wheel speeds. It was braked from $70 \mathrm{~km} / \mathrm{h}$ with braking time of 11 seconds. Figure 10 clearly shows that front wheel pressure was modulated to meet brake demand in terms of brake pedal travel. After $\mathrm{t}=4$ seconds, the pedal was held at about $16.5 \mathrm{~mm}$ and returned to initial position when $t>14$ seconds. Initially, the front pressure rose with pedal travel and was

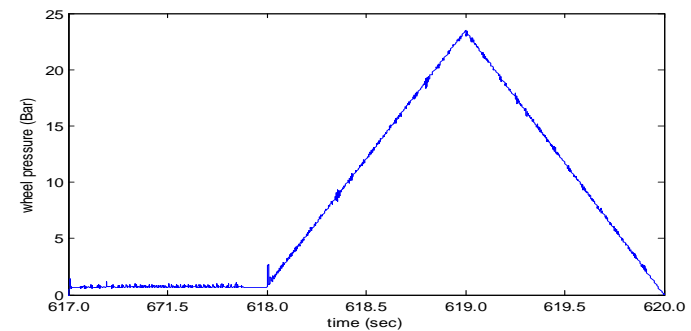

Figure 9. Controlled wheel pressure in mixed-mode braking system

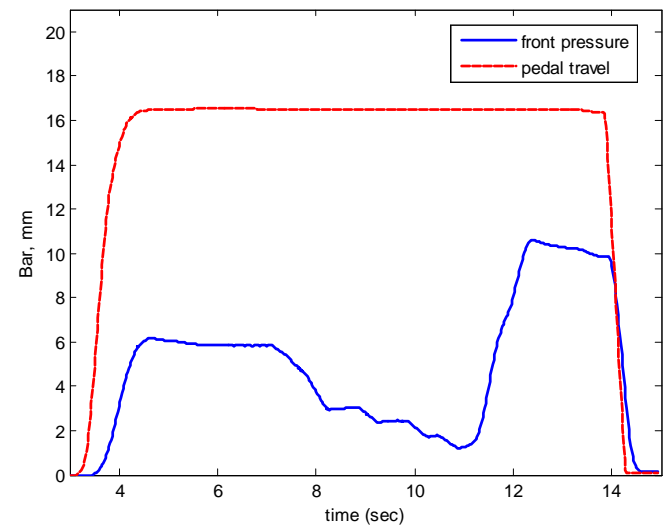

Figure 10. Pedal travel and front pressure of Auris braking system

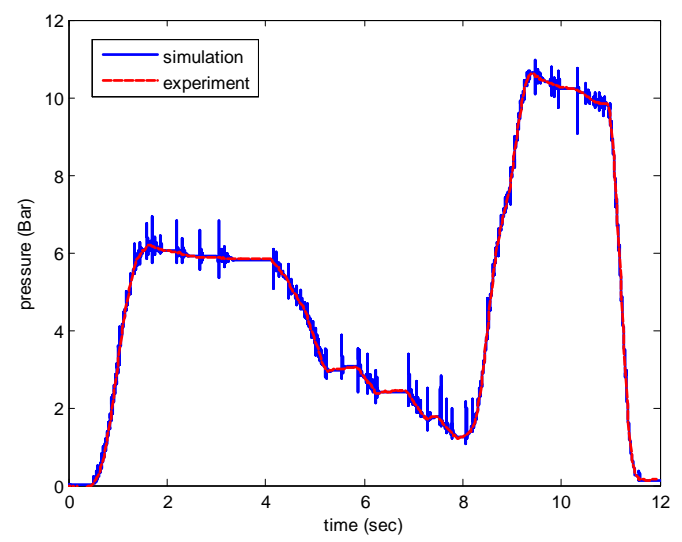

Figure 11. Comparing model output with the experimental result on Auris hybrid maintained at about 6 bar. However, it was gradually reduced after $\mathrm{t}=7$ seconds who indicates that regenerative brake portion increased. At lower vehicle speeds, the front pressure was increased to 10 bar again to stop the vehicle completely. This front pressure response is then used to validate the model of a proposed hydraulic brake system. As shown in Figure 11, the model successfully follows the Auris front pressure despite pressure spikes appeared in the output. Hydraulic pressure overshot could be lowered by reducing duty cycle of PWM voltage to the coil as shown in Figure 12. Here, the set point is 10 bar and three PWM signals were compared and signal with the $25 \%$ duty cycle exhibit lower overshot value.

The second braking data was obtained from Nissan Leaf EV. The brake pedal travel demanded by the driver and resulted from front brake pressure are shown in Figure 13. Compared with Auris Hybrid, the brake condition is more challenging since it exhibited fluctuating brake demand. Pedal force from the driver was then converted into total braking torque demand as shown in Figure 14. Next, it was split into regenerative and hydraulic front wheel brakes. In response to driver demand, the regenerative torque also oscillated during braking period and

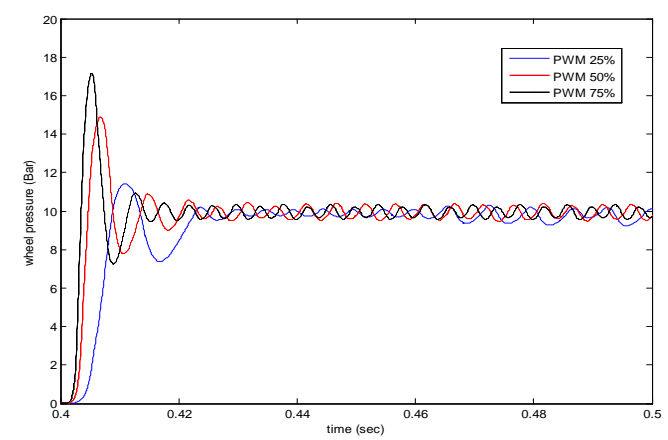

Figure 12. Wheel pressure responses for different PWM ratios

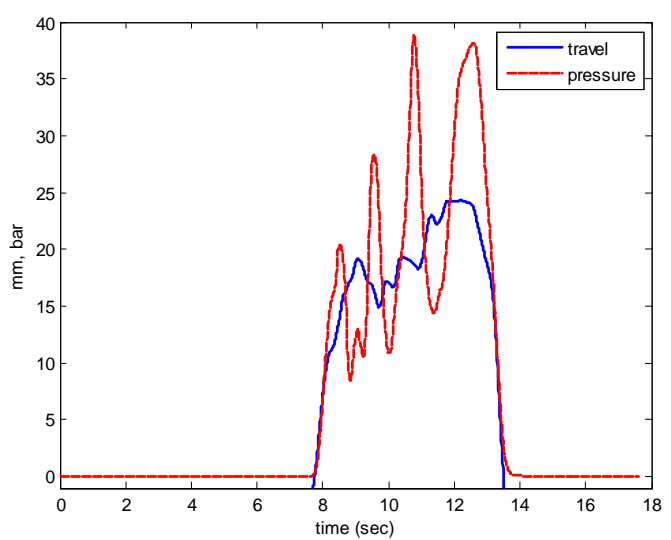

Figure 13. Pedal travel and front pressure of Nissan Leaf braking system 
tried to optimize energy recovery as shown in the figure.

The front brake pressure became set point in simulation model and was plotted together with a pressure response in Figure 15. As can be seen, the pressure response generated by the model closely followed the set point. An interesting condition was observed in which the pressure can not be increased to meet the demand around $\mathrm{t}=$ 12 sec. Observing responses in Figure 16, this was caused by source pressure in the accumulator

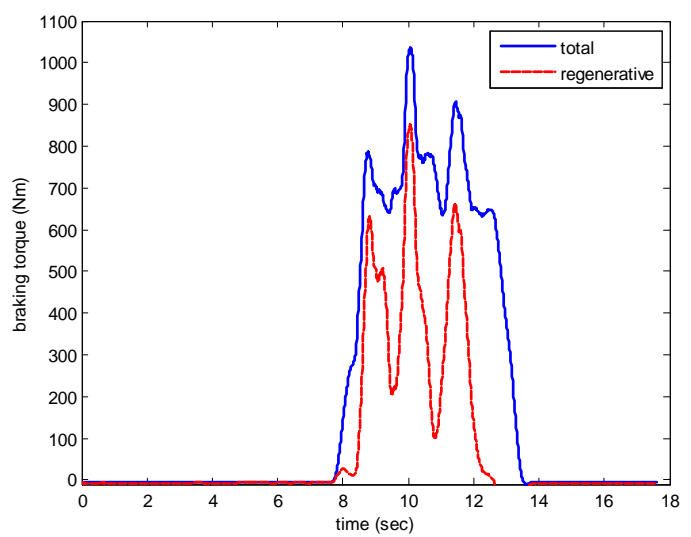

Figure 14. Pedal travel and front pressure of Nissan Leaf braking system

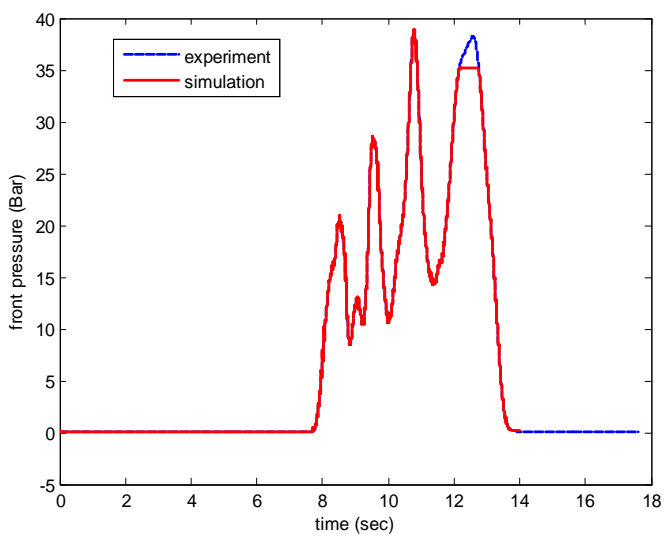

Figure 15. Comparing model output with the experimental result on Leaf EV

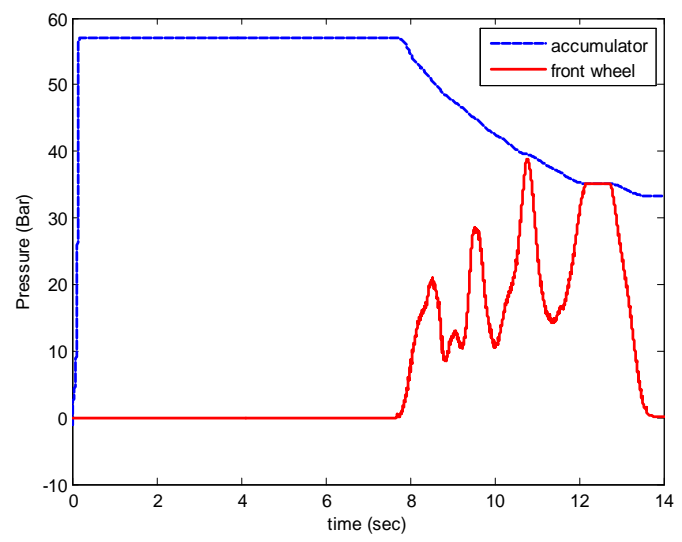

Figure 16. Effect of source pressure on brake response decreased significantly as a result from pressure dump control discussed in section III.

\section{Conclusions}

The applications of direct torque control and pressure control criteria on mixed-mode braking system has been explored through simulation as well as experiment. The conclusions to be made are: first, regenerative braking torque is maximized and friction braking must provide the difference with driver demand under all operating conditions. Second, a $15 \mathrm{~kW} 1500 \mathrm{rpm}$ induction motor satisfies the most braking demand in the FTP drive cycle while the friction portion is dominant at low speeds in that cycle when regenerative braking is ineffective. Third, regenerative torque generated contains a high frequency ripple but this does not affect vehicle deceleration. Finally, a lower ratio of PWM signal is better to control pressure because it generates lower of overshoot.

\section{REFERENCES}

[1] Zaini Dalimus, "Braking System Modeling and Brake Temperature Response to Repeated Cycle," Journal of Mechatronics, Electrical Power, and Vehicular Technology, 2014, vol.05, pp. 123-128. DOI:10.14203/j.mev.2014.v5.123-128.

[2] Chau, K. T et al., "Overview of permanentmagnet brushless drives for electric and hybrid electric vehicles," IEEE Transactions on Industrial Electronics, 2008, 55, (6), pp. 2246-2257. DOI:10.1109/TIE.2008.918403.

[3] Dorrell, D.G et al., D.A.: "Comparison of different motor design drives for hybrid electric vehicles," Energy Conversion Congress and Exposition, 2010, pp. 3352 3359. DOI:10.1109/ECCE.2010.5618318.

[4] Khoucha, F et al., M.E.H. : "Improved Sensorless DTC Scheme for EV Induction Motors," 2007 IEEE International Electric Machines \& Drives Conference, Antalya, 2007, pp. 1159-1164. DOI: 10.1109/IEMDC.2007.383594.

[5] Vyncke, T. J et al., "Direct torque control of permanent magnet synchronous motors - an overview," 3rd IEEE Benelux Young Researchers Symposium in Electrical Power Engineering, Ghent, Belgium, 2006, pp. 1-5. DOI: 10.1109/IECON.2009.5414686

[6] Ohtani, Y et al., "Development of an Electrically-Driven Intelligent Brake Unit," SAE Techical Paper, 2011-01-0572. 2007. DOI: 10.4271/2011-01-0572.

[7] Yuan, D et al., "Simulation of hydraulic brake built-in test system for a certain UAV," 
Control Conference (CCC), 2013 32nd Chinese, Xi'an, 2013, pp. 801-804.

[8] Park, M. et al., "Development of the control logic of electronically controlled hydraulic brake system for hybrid vehicle," $S A E$ Technical Paper 2009-01-1215, 2009, pp. 17. DOI: $10.4271 / 2009-01-1215$.

[9] Aoki, Y et al.,"Development of hydraulic servo brake systemfor cooperative control with regenerative brake," SAE Technical Paper 2007-01-0868, 2007, pp. 1-9. DOI: 10.4271/2007-01-0868

[10] Albrichsfeld, C. V.and Karner, J.: "Brake system for hybrid and electric vehicles," SAETechnical Paper2009-01-1217, 2009, pp. 1-7. DOI: 10.4271/2009-01-1217.

[11]Lei, Z., Yugong, Let al., "A novel brake control strategy for electric vehicles based on slip trial method," Vehicular Electronics and Safety, 2007. ICVES. IEEE International Conference on, Beijing, 2007, pp. 1-6. DOI: 10.1109/ICVES.2007.4456364.

[12] Tremblay and O., Dessaint, L. A.: "Experimental validation of a battery dynamic model for EV applications," World Electric Vehicle Journal, 2009, 3, pp. 1-10

[13] Ghorbani, M. Jet al.,."Direct torque control of induction motor by Active Learning Method," Power Electronic \& Drive Systems \& Technologies Conference (PEDSTC), 2010 1st, Tehran, Iran, 2010, pp. 267-272. DOI: 10.1109/PEDSTC.2010.5471817.

[14]Qi, X. et al.,"Influence of hydraulic ABS parameters on solenoid valve dynamic response and braking effect," SAETechnical Paper2005-01-1590, 2005, pp. 1-12. DOI: 10.4271/2005-01-1590.

[15]Zaini, Z.et al.,"Mixed-mode braking system for road vehicles with regenerative braking," 6th European Conference on Braking, Lille, France, 2010, pp. 115-122.

\section{NOMENCLATURE}

\begin{tabular}{|c|c|}
\hline Variable & Definition \\
\hline$i_{d}$ & d-axis component of current \\
\hline $\mathrm{i}_{\mathrm{q}}$ & q-axis component of current \\
\hline$\Psi_{\mathrm{d}}$ & d-axis component of flux \\
\hline$\psi_{\mathrm{q}}$ & $\mathrm{q}$-axis component of flux \\
\hline$\Psi_{\mathrm{m}}$ & Magnetizing flux \\
\hline$\psi_{\mathrm{s}}$ & Stator flux linkage \\
\hline$\psi_{\mathrm{r}}$ & Rotor flux linkage \\
\hline$u_{d}$ & d-axis component of voltage \\
\hline $\mathrm{u}_{\mathrm{q}}$ & q-axis component of voltage \\
\hline $\mathrm{L}_{\mathrm{d}}$ & d-axis component of inductance \\
\hline $\mathrm{L}_{\mathrm{q}}$ & q-axis component of inductance \\
\hline $\mathrm{L}_{\mathrm{s}}$ & Stator leakage inductance \\
\hline $\mathrm{L}_{\mathrm{r}}$ & Rotor leakage inductance \\
\hline $\mathrm{L}_{\mathrm{m}}$ & Mutual inductance \\
\hline $\mathrm{R}_{\mathrm{s}}$ & Stator resistance \\
\hline$\sigma$ & Leakage factor \\
\hline$\omega_{\mathrm{r}}$ & Rotor speed \\
\hline$\delta_{\psi}$ & Load angle \\
\hline $\mathrm{T}_{\mathrm{e}}$ & Electromagnetic torque \\
\hline $\mathrm{V}_{\text {batt }}$ & Battery voltage \\
\hline $\mathrm{E}_{0}$ & Battery constant voltage \\
\hline it & Actual battery charge \\
\hline $\mathrm{i}^{*}$ & Filtered current \\
\hline $\mathrm{Q}_{\mathrm{b}}$ & Battery capacity \\
\hline $\operatorname{Exp}(\mathrm{t})$ & exponential zone voltage \\
\hline $\mathrm{R}_{\mathrm{i}}$ & Internal resistance \\
\hline $\mathrm{K}$ & polarisation constant \\
\hline Q & Volumetric flow rate \\
\hline $\mathrm{C}_{\mathrm{d}}$ & Coeeficient of discharge \\
\hline$\rho$ & Fluid density \\
\hline $\mathrm{A}_{0}$ & cross-sectional area of the orifice \\
\hline $\mathrm{P}_{1}$ & Fluid upstream pressure \\
\hline $\mathrm{P}_{2}$ & Fluid downstream pressure \\
\hline $\mathrm{i}$ & Coil current \\
\hline $\mathrm{U}$ & Coil voltage \\
\hline $\mathrm{L}$ & Coil inductance \\
\hline $\mathrm{R}$ & Coil resistance \\
\hline $\mathrm{m}$ & Plunger mass \\
\hline $\mathrm{K}$ & Spring constant \\
\hline $\mathrm{b}$ & Viscous damping constant \\
\hline $\mathrm{x}$ & Plunger position \\
\hline $\mathrm{v}$ & Pluger speed \\
\hline$F_{f}$ & Frictional force \\
\hline $\mathrm{F}_{\mathrm{m}}$ & Magnetic force \\
\hline $\mathrm{F}_{\mathrm{p}}$ & Hydrokinetic force \\
\hline
\end{tabular}

